\title{
Robustness of an existing pre-stressed concrete bridge
}

\author{
Hugo Guimarães, João Fernandes \& José C.Matos \\ University of Minho, ISISE, Guimarães, Portugal
}

\begin{abstract}
Robustness has been appointed as a desirable property of systems in order to avoid significant indirect consequences caused by extreme events. In fact, robustness is usually related to global failure or collapse. Nevertheless, its definition is not consensual, having led researchers to propose several quantitative measures. In this work, an intuitive framework for the assessment of robustness as a probabilistic performance indicator of bridges to be applied either to ultimate limit states or service limit state is discussed. The research strategy consists in a review of the state-of-art of robustness of structures, aiming to identify the suitable quantitative procedures to assess system robustness and its contributing attributes. A non-linear finite element model of an existing pre-stressed concrete bridge was used to assess bridge structural performance when it is subjected to several damage scenarios. By means of a probabilistic approach, the load carrying capacity and structural safety are evaluated through advanced reliability analysis techniques.
\end{abstract}

\section{INTRODUCTION}

Robustness of structures has been recognized over the years as interesting research topic due to the collapse of big structural systems in which the consequences were considered unacceptable concerning its initial damage. Indeed, several system failures have been occurring, such as: (1) Ronan Point Building in 1968, London; (2) New World Hotel in 1985, Singapura; (3) The Highland towers in 1993, Kuala Lumpur; (4) Sampoong Department Store in 1995, Seul; (5) World Trade Center in 2001, New York; (6) The Torch Tower in 2015, Dubai and (7) The Adress Hotel in 2015, Dubai.

Structural robustness began to be seriously studied after the massive disaster of World Trade Centre collapse. Another reason for a renewed interest of robustness analysis were derived for failures due to unexpected loads, design errors, errors during execution, unforeseen deterioration and poor maintenance (Canisius et al., 2007). In this context, a workshop carried by JCSS in collaboration with IABSE at the Building Research Establishment in London, UK (December 2005) gathered 50 experts, from research institutions, companies and government, to discuss issues related with robustness. The conclusions leaded to a general consensus that the present situation with regard to ensuring sufficient structural robustness through codes and standards was highly unsatisfactorily. As a consequence, a joint European project in Robustness was created, namely the COST action TU06010 - Robustness of Structures.

The present work aims to develop a framework for the assessment of robustness as a performance indicator of bridges. In this way, a non-linear finite element model (FEM) of an existing pre-stressed concrete bridge, combined with probabilistic approaches, is carried out in order to assess bridge' safety. This paper is organized as follows: in chapter
2 , general concepts and existing approaches regarding robustness are presented; probabilistic techniques to assess existing bridges are highlighted in chapter 3; later, theoretical concepts presented in previous chapters are applied in a case study. Finally, in the last chapter, conclusions are drawn and future developments are pointed out.

\section{ROBUSTNESS}

\subsection{General Concepts}

In general, robustness can be defined as a capacity that a certain structure has to support a certain amount of damage without occurring global collapse. Starossek and Haberland (Starossek \& Haberland, 2010) presented several definitions of robustness in civil engineering domain. The same authors also discuss several terms related with robustness, such as:

- Exposure - possibility of a structure to be affected by a threat during its life-cycle;

- Vulnerability - susceptibility of a structure to be damaged by an exposure;

- Damage tolerance - ability of a structure to survive once it is damaged;

- Redundancy - availability of alternative paths for a load to be transferred from a point of application to a point of resistance;

- Ductility - ability of a structure to suffer plastic deformations without occurring rupture;

- Reliability - ability of a structure to perform its intended function for a specific period of time under certain conditions. 


\subsection{Robustness Measures}

Regarding the quantification of robustness, several approaches have been proposed by different researchers. These methodologies can be divided into the following levels of increasing complexity: deterministic, probabilistic and risk-based way. Concerning deterministic approaches, the most relevant works are presented by Frangopol and Curley,1987 (Frangopol \& Curley, 1987), Biondini and Restelli, 2008 (Biondini \& Restelli, 2008), Starossek and Haberland,2011 (Starossek \& Haberland, 2011) and Cavaco,2013 (Cavaco, 2013). According to a probabilistic perspective, additional insights are presented by Frangopol and Curley,1987 (Frangopol \& Curley, 1987), Fu and Frangopol,1990 (Fu \& Frangopol, 1990) Lind,1995 (Lind, 1995) and Goshn and Moses, 1998 (Ghosn \& Moses, 1998). Lastly, a complex and comprehensive framework to assess robustness based on risk is presented by (Baker et al.,2008).

\section{PROPOSED FRAMEWORK}

Despite this intense effort of the research community, both structural reliability analysis and robustness assessment require a comprehensive understanding of crucial topics, hindering their practical application in real situations. Indeed, the most complete approach, namely, the risk-based robustness, usually surpasses the structural engineers scope, since modelling system consequences is not a trivial task. In the remaining approaches, handling with more than one hazard is also very limited. Besides that, ranges of existing robustness indexes still need to be normalized from 0 (null) to 1 (full robustness), facilitating comprehension and comparison.

In this sense, herein, a reliability-based robustness assessment framework is introduced, seeking to combine the merits of existing knowledge, in order to obtain a new robustness index to be applied at two performance levels: structural behavior at ultimate or service limit states.

The proposed robustness index aims to depict the structural performance by assessing a wise selection of four different attributes or performance indicators according to a predefined goal. In this approach, robustness is computed as equal to the area of a quadrilateral, whose sides' lengths represent a selected performance indicator. With the aim of assessing the structural performance under degradation phenomena, four hazardous events are studied. Hence, for each scenario a probabilistic performance indicator, namely, comparison of reliability indexes corresponding to undamaged and damage situations is computed.
In the light of life-cycle perspective, those performance indicators are time-dependent, so that they can be computed to predict performance decay. This approach can easily achieve a quantitative measure to support road manager's decisions regarding the allocation of resources for investments and maintenance, as well as the mitigation of the consequences. In fact, each performance indicator can be weighted according to a qualitative risk matrix, taking to account indirect consequences of failure.

With regard to structural reliability, since the expected probability of failure is low, crude Monte Carlo requires a large number of numerical simulations in order to solve the convolution integral. To tackle this, the performance limit function can be approximated by the so-called meta-models, namely, quadratic response surfaces, polynomial chaos, and so on. Herein, quadratic response surfaces (RS), which are able to efficiently cope with highly nonlinear relations between inputs and outputs, are used. To do so, an adaptive procedure based on Monte Carlo realizations inspired on schemes proposed by Bucher and Bourgund (Bucher \& Bourgund, 1990) and also Rajashekhar and Ellingwood (Rajashekhar \& Ellingwood, 1993) is accomplished. In this approach, a stepwise regression, which combines forward and backward regression methods to select the most important terms according to their statistical significance, is used to minimize the approximation error. This RS is built based on an initial experimental design (ED) referred to search domain, a Monte Carlo sample, whose realizations are dispersed with a given parameter from mean value according to their bias.

Both design point coordinates and probability of failure are computed through the first reliability method (FORM). Regarding the following steps, new sampling points are added to enrich the ED around the design point. The procedure is stopped when a convergence criterion is satisfied, which is based on reliability index relative error tolerance between consecutives iterations. In this procedure, the limit state function can be defined according to problem definition. Herein, a performance limit function based on the difference of resisting and acting loads, $G(X)=R(X)-S(X)$, is accomplished. 


\section{CASE STUDY}

\subsection{Description of the structure}

The case study concerns a highway overpass idealized as a three-span pre-stressed concrete continuous rigid-frame, whose spans' length are 18, 27.8 and 18 $\mathrm{m}$, respectively. This viaduct is composed by precast girder elements supported by the abutments and the piers. A longitudinal view of the bridge is shown in figure 1 .

The deck's cross-section comprises three precast I shape $1.5 \mathrm{~m}$ deep beams spaced by $3 \mathrm{~m}$ and cast-inplace $0.20 \mathrm{~m}$ thick and $8.9 \mathrm{~m}$ width reinforced concrete slab. The piers are monolithically connected to the deck and fixed to footings. Both $15 \mathrm{~m}$ height piers have a rectangular cross section with 2,40 per 0,80 meters.

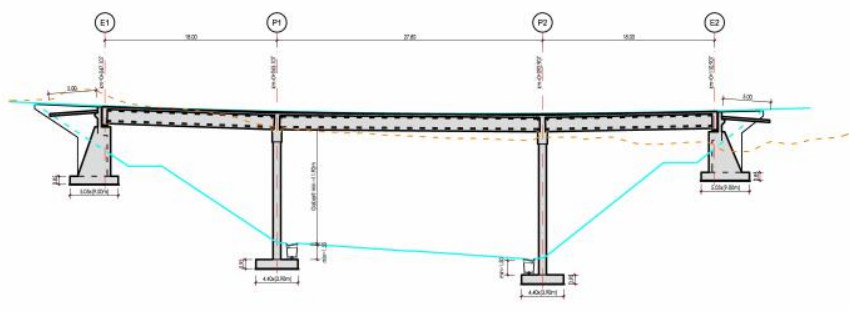

Figure 1 - Longitudinal view of the bridge

\subsection{Probabilisitic model}

The probabilistic values for the mechanical properties of the materials as well as the applied loads are presented in table 1 . All the probabilistic parameters are represented by their mean values and coefficient of variation $(\mathrm{CoV})$. A correlation for the material was considered too. It was considered correlation between compressive strength and Young modulus $(r=0,90)$, correlation between compressive strength and the tensile strength $(\mathrm{r}=0,70)$ and yielding strength and ultimate strength of pre-stressing steel $(\mathrm{r}=0,80)$.

For the load scenario, the dead loads were divided into: (1) the initial dead loads before concreting castin-place slab, $\mathrm{G}_{\mathrm{i}}$; (2) additional dead loads after concreting remaining parts, Ga. For traffic loads, load model 1(LM1), provided by Eurocode(CEN, 1991), was considered with: (1) uniformly distributed load (UDL),q; (2) tandem system including two axles (TS), Q.

\subsection{Damage Scenarios}

In this section, idealized damage scenarios are formulated assuming a degradation phenomenon and soil instability at footings. Knowing that bridge presents a critical cross section with low capacity of redistributing bending moments, the main goal is to analyze the ability to cope with additional damage scenarios. In fact, although the structure presents a significant reserve capacity, it does not present a ductile rupture since there is no strands yielding. With this, considered scenarios were the following: (i) loss of cross section in the tendons; (ii) deterioration of the precast concrete; (iii) soil settlement at pier due to lack of bearing capacity; (iv) combination of the first and second damage scenarios.

\subsection{Numerical model}

As mentioned, a non-linear analysis through DIANA software was carried out in order to assess the performance indicators of the bridges at ultimate limit state. Regarding the type of analysis, a 2D non-linear structural analysis was performed with class III beam elements based on Mindlin-Reissner theory with incremental load steps until failure. The adopted method to solve the non-linear problem was the Modified Newton-Raphson method, at the first iteration of each step.

Concerning materials constitutive laws, a total strain fixed crack model was adopted, in which for tensile behavior a linear ultimate strain based was implemented and an ideal behavior for concrete compression. Regarding the reinforcing steel and prestressing steel, a tri-linear diagram was adopted. In figure 2, a numerical model through DIANA software is presented.

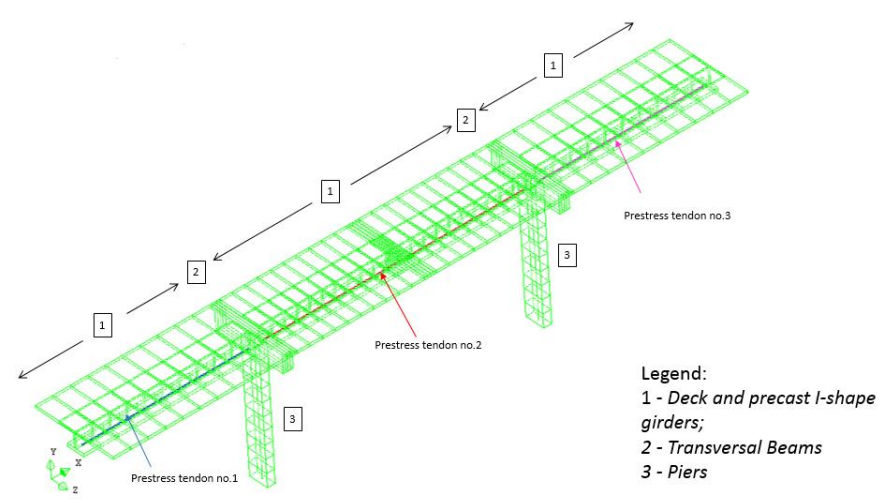

Figure 2 - Numerical Model of the bridge

\subsection{Obtained Results}

Before performing a probabilistic analysis, in order to obtain the reliability index, firstly, a deterministic analysis was made. In figure 3 , a load-deflection curve is presented. The mechanism of failure were a three hinge plastic formation with the yielding of the 
steel denoting a ductile behavior. The maximum load factor obtained was 5.60. For a probabilistic approach, a reliability index, for damaged and undamaged situation, was obtained. In table 2, the obtained reliability indexes can be seen.

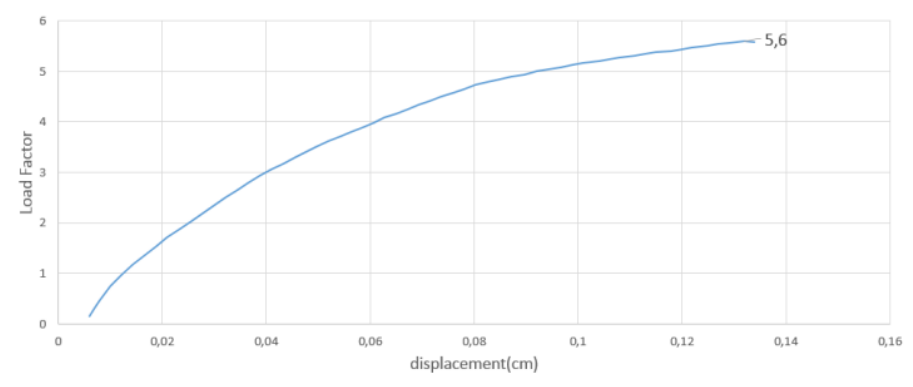

Figure 3 - Load-deflection curve

Table 1 - Material Properties

\begin{tabular}{|c|c|c|c|c|c|}
\hline Description & Random Variable & Notation & Distr. Type & Mean Value & Coefficient of Variance \\
\hline \multirow{3}{*}{ Cast in-situ C30/37 } & $\begin{array}{l}\text { Concrete compres- } \\
\text { sive strength }\end{array}$ & $\mathrm{f}_{\mathrm{c}}$ & Normal & $30 \mathrm{MPa}$ & $12 \%$ \\
\hline & $\begin{array}{l}\text { Concrete tensile } \\
\text { strength }\end{array}$ & $\mathrm{f}_{\mathrm{ct}}$ & Lognormal & $2.90 \mathrm{MPa}$ & $20 \%$ \\
\hline & $\begin{array}{l}\text { Concrete elasticity } \\
\text { modulus }\end{array}$ & $\mathrm{E}_{\mathrm{c}}$ & Normal & $33 \mathrm{GPa}$ & $8 \%$ \\
\hline \multirow{3}{*}{ Precast girder $\mathrm{C} 45 / 55$} & $\begin{array}{l}\text { Concrete compres- } \\
\text { sive strength }\end{array}$ & $\mathrm{f}_{\mathrm{c}}$ & Normal & $45 \mathrm{MPa}$ & $9 \%$ \\
\hline & $\begin{array}{l}\text { Concrete tensile } \\
\text { strength }\end{array}$ & $\mathrm{f}_{\mathrm{ct}}$ & Lognormal & 3,70 MPa & $20 \%$ \\
\hline & $\begin{array}{l}\text { Concrete elasticity } \\
\text { modulus }\end{array}$ & $\mathrm{E}_{\mathrm{c}}$ & Normal & $36 \mathrm{GPa}$ & $8 \%$ \\
\hline \multirow{3}{*}{ A500 } & $\begin{array}{l}\text { Steel yielding } \\
\text { strength }\end{array}$ & $\mathrm{f}_{\mathrm{sy}}$ & Normal & $560 \mathrm{MPa}$ & $5.35 \%$ \\
\hline & $\begin{array}{l}\text { Steel ultimate } \\
\text { strength }\end{array}$ & $\mathrm{f}_{\mathrm{su}}$ & Normal & $650 \mathrm{MPa}$ & $6.0 \%$ \\
\hline & Steel ultimate strain & $\varepsilon_{\mathrm{su}}$ & Normal & $10,11 \%$ & $15 \%$ \\
\hline \multirow{3}{*}{ A1670/1860 } & $\begin{array}{l}\text { Strands yielding } \\
\text { strength }\end{array}$ & $\mathrm{f}_{\mathrm{py}}$ & Normal & $1737 \mathrm{MPa}$ & $2.5 \%$ \\
\hline & $\begin{array}{l}\text { Strands } \\
\text { strength }\end{array}$ & $\mathrm{f}_{\mathrm{pu}}$ & Normal & $1935 \mathrm{MPa}$ & $2.5 \%$ \\
\hline & $\begin{array}{l}\text { Strands } \\
\text { strain } \\
\end{array}$ & $\varepsilon_{\mathrm{pu}}$ & Normal & $5.00 \%$ & $8 \%$ \\
\hline \multirow{3}{*}{ Pre-stress Force } & $\begin{array}{l}\text { Prestressing Stress } \\
(\text { span } 1)\end{array}$ & $\mathrm{P} 1$ & Normal & $1046 \mathrm{MPa}$ & $1.5 \%$ \\
\hline & $\begin{array}{l}\text { Prestressing Stress } \\
(\operatorname{span} 1)\end{array}$ & $\mathrm{P} 2$ & Normal & $1087 \mathrm{MPa}$ & $1.5 \%$ \\
\hline & $\begin{array}{l}\text { Prestressing Stress } \\
(\operatorname{span} 3)\end{array}$ & P3 & Normal & $1046 \mathrm{MPa}$ & $1.5 \%$ \\
\hline \multirow{3}{*}{ Loads } & Self-weight & $\mathrm{G}_{\mathrm{i}}$ & Normal & $25,75 \mathrm{kN} / \mathrm{m}^{3}$ & $8 \%$ \\
\hline & $\begin{array}{l}\text { Additional dead } \\
\text { loads }\end{array}$ & $\mathrm{G}_{\mathrm{a}}$ & Normal & $26,25 \mathrm{kN} / \mathrm{m}^{3}$ & $10 \%$ \\
\hline & Traffic loads & Q & Gumbel & $\begin{array}{l}500 \mathrm{kN}(\mathrm{TS}) \\
37,75 \mathrm{kN} / \mathrm{m}(\mathrm{UDL})\end{array}$ & $10 \%$ \\
\hline
\end{tabular}

Table 2- Obtained reliability indexes for the considered scenarios

\begin{tabular}{ll}
\hline Intact & $\beta=10.400$ \\
\hline Scenario 1 & $\beta=6.277$ \\
\hline Scenario 2 & $\beta=9.838$ \\
\hline Scenario 3 & $\beta=9.679$ \\
\hline Scenario 4 & $\beta=4.510$ \\
\hline
\end{tabular}


Analysing the obtained reliability indexes, it can be seen that for an intact structure the obtained value is extremely high. This is due to its redundancy, the large amount of steel that the bridge is composed and by the fact that the pre-stress steel commands the structure at ultimate limit state. This can be clearly seen when analyzing the result obtained for the first scenario. With a loss of cross section in prestressing steel, there is a considerable decrease of the obtained reliability index. In the other way round, for the scenario 2, deterioration of concrete, the influence is almost null. The same happens for scenario 3 , the pier settlement, once this is an imposed displacement being the effect on ultimate limit state analysis is almost null. The scenario 4 presents the lower value of the reliability index once it is a conjugation of scenarios 1 and 2 .

\section{CONCLUSION}

A reliability-based robustness assessment framework to evaluate bridge's safety is introduced. The main point of the procedure is to facilitate the understanding regarding the vulnerability of different hazardous events.

Herein, the performance of a reinforced concrete bridge under several degradation phenomena is studied. Indeed, this paper presents some preliminary studies concerning reliability analysis. The main goal is to facilitate the understanding of some attributes regarding robustness, aiming to propose a versatile framework to evaluate robustness according to a choice of key performance indicators. Regarding reliability analysis, used approach intends to reduce computational time and also to reproduce an explicit limit state function avoiding overfitting and diminishing approximation error. In fact, this methodology can be improved by introducing some features: i) use of pseudo random-generators to populate region of failure; ii) establishing cross-validation procedures; iii) considering model error as random variable; iv) bootstrap sampling to estimate boundaries of probability of failure. Finally, the application of these framework with additional improvements is to be applied in a near future.

\section{ACKNOWLEDGMENTS}

The authors would like to thank ISISE - Institute for Sustainability and Innovation in Structural Engineering (PEst-C/ECI/UI4029/2011 FCOM-01-0124FEDER-022681), FCT- Portuguese Scientific Foundation for the research grant PD/BD/113677/2015.
This study also received funding from the European Union's Seventh Framework Programme for research, technological development and demonstration under grant agreement No. 606229. Also the collaboration and information provided by the professor António Abel Henriques is gratefully acknowledged.

\section{REFERENCES}

Uwe Starossek and Marco Haberland. Disproportionate collapse: terminology and procedures. Journal of Performance of Constructed Facilities, 24(6):2010.

Dan M Frangopol and James P Curley. Effects of damage and redundancy on structural reliability. Journal of Structural Engineering, 113(7):1987.

Uwe Starossek and Marco Haberland. Approaches to measures of structural robustness. Structure and Infrastructure Engineering, 7(7-8):2011.

Eduardo Cavaco. Robustness of corroded bridges, PhD thesis, Universidade Nova de Lisboa,. 2013.

Gongkang $\mathrm{Fu}$ and Dan M Frangopol. Balancing weight, system reliability and redundancy in a multiobjective optimization framework. Structural Safety, 7(2):1990.

Niels C Lind. A measure of vulnerability and damage tolerance. Reliability Engineering \& System Safety, 48(1):1995.

Michel Ghosn and Fred Moses. Redundancy in highway bridge superstructures. 1998.

CG Bucher and U Bourgund. A fast and efficient response surface approach for structural reliability problems. Structural safety, 7(1):1990.

Malur R Rajashekhar and Bruce R Ellingwood. A new look at the response surface approach for reliability analysis. Structural safety, 12(3):1993.

CEN. Eurocode 1: Actions on structures, Part 2: Traffic loads on bridges. Brussels: European Standard 1991. 
